\title{
Microclimatic Modeling and Analysis of a Fog- Cooled Naturally Ventilated Greenhouse
}

\author{
Debajit Misra, Sudip Ghosh*
}

\author{
Department of Mechanical Engineering, IIEST, Shibpur, India
}

\begin{abstract}
In the present paper, a thermal model has been presented for predicting the thermal environment inside a fog cooled naturally ventilated greenhouse. Experiments were conducted on a polyethylene covered greenhouse having $250 \mathrm{~m}^{2}$ ground area located at Coochbehar (latitude: $26.2^{\circ} \mathrm{N}$, longitude: $89^{\circ} \mathrm{E}$ ), West Bengal, India. The greenhouse was cooled by intermittent fogging with three distinct fogging cycles during the experiments. The greenhouse air temperature profiles as predicted by theoretical model were validated for different fogging cycle configurations. The model prediction and experimental results build up a good match (co-efficient of correlation was in range of 0.85 to 0.92). It was observed that fogging cycle configuration (spray time and spray interval combination) influences greatly the cooling performance of the fogging system. Further analysis revealed that greenhouse temperature could be maintained $2-4^{\circ} \mathrm{C}$ below the ambient temperature by employing suitable fogging cycle, maintaining the relative humidity within acceptable level.
\end{abstract}

Keywords-Cooling, Fogging cycle, Greenhouse, Natural ventilation, Spray time.

\section{INTRODUCTION}

Greenhouse is meant to provide optimum growing conditions of the plants inside it all over the seasons. In cold countries, the primary objective of the greenhouse is to increase the air temperature by the principle of "greenhouse effect" for sustainable growth of plants. However, a country in subtropical or tropical areas, temperature reduction is the main objective rather than the "greenhouse effect", which has been provided by "shading effect" (checking solar radiation) during the periods of high radiation, or providing a suitable air exchange, or incorporating evaporative type cooling. Nowadays, in hot climatic regions, evaporative cooling with some form of ventilation (natural or fan-induced) is used extensively to provide a suitable microclimate for plant growth during the hot summer season. In most of the cases, fan pad evaporative cooling is a common practice of greenhouse cooling. But fan pad cooling system creates temperature and humidity gradients along the length of the greenhouse; also the total equipment cost for the system is high. In order to maintain uniform temperature and humidity all through the greenhouse, fog cooling can be employed. It is based on fine water dispersion into the air stream to increase the heat exchange between water and air. Air circulation is very much important for fog cooled greenhouse and can be achieved by fan induced ventilation or natural ventilation. To reduce electric power consumption, the fog cooling system is often incorporated with natural ventilation, achieved by multiple ventilators which allow air to enter and leave the greenhouse.

This paper presents a thermal model of a fog cooled greenhouse located in the Indian subcontinent. The prime focus of the study was to investigate the fogging effect on a greenhouse micro-climate in a plastic greenhouse during summer under natural ventilation. To serve this purpose, a greenhouse equipped with fog system was selected, a thermal model has been established to characterize the fogging system, experiments were conducted and finally the model was validated with experimental data.

Many researches carried out studies on greenhouse cooling by employing fogging system. Arbel et al. (1999) developed a mathematical model to characterize the fog cooling system. They conducted an experiment in a fourspan greenhouse which was equally divided into two parts. Each part of the greenhouse was equipped with fog system and with fan-pad evaporative cooling system. They did a comparative study by operating each system in the two parts alternately. It was observed that fog cooling system performed better than fan-pad evaporative cooling system. Arbel et al.(2003) presented a cooling arrangement for a greenhouse combined with high pressure fogging and faninduced ventilation system. They reported that greenhouse air temperature and relative humidity can be kept at $28{ }^{\circ} \mathrm{C}$ and $80 \%$ respectively during mid-summer with such type of cooling arrangement. Ahmed et al. (2006) established a dynamic model for a naturally ventilated fog cooled greenhouse. The developed model was capable of predicting the greenhouse air temperature, plant temperature, cover temperature, floor surface temperature, relative humidity, transpiration and evaporation rate. The model results have been compared with an experimental greenhouse installed in Tokyo. Abdel-Ghany et al. (2006) suggested a new expression of cooling efficiency for a fogcooled greenhouse system. They investigated the cooling efficiencies for different fogging cycles. Öztürk (2003) 
carried out an experiment in a multi-span plastic greenhouse to determine the efficiency of the fogging system. The average represented fogging system efficiency was $50.5 \%$.Ishigami et al. (2014)experimented on two separate fog- cooled greenhouses, each having $26.4 \mathrm{~m}^{2}$ floor area. They observed that twin fluid nozzle system had higher evaporation rate and lower degree of wetting of plant foliage compared to single fluid nozzle system. It was observed that twin fluid nozzle system produced the same cooling effect as single fluid nozzle system. Li and Willits (2008) compared the performance of a low pressure (4.05 bar) fogging system with high pressure (40.5 bar) system. They observed that high-pressure systems provide better cooling than low-pressure systems, though highpressure systems required much higher initial investment and operational costs. The cooling and evaporation efficiencies of the two systems were also compared. controlled by low pressure fog cooling system; horizontal thermal shading screens were placed at gutter level and by adjusting the openings of side and roof vents. The side vents were set on both north and south walls; each side having of $14.4 \mathrm{~m}^{2}$ area $(0.9 \mathrm{~m} \times 16 \mathrm{~m})$ and roof vent area was $16 \mathrm{~m}^{2}$. The side vents were covered with insect proof net. The greenhouse side vent opening can be regulated by roll up curtain as per ventilation requirement.

Fogging System: The main elements of fogging system in the greenhouse are a pump unit and Fogging lines. Pump unit consists of pump, a water reservoir, a water softener, a fine filter, and a pressure adjusting regulator, valve, and the fogging lines consist of main pipe line, distributor line, LDPE (low density poly-ethylene) pipe

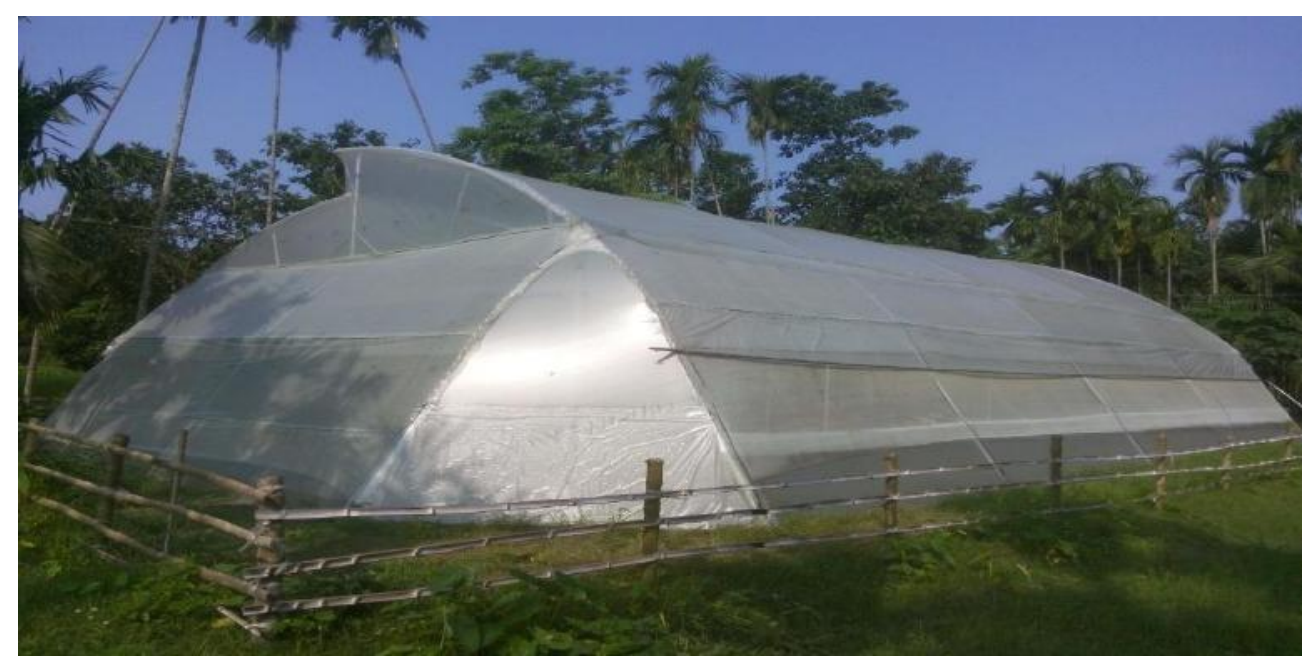

Fig.1: Experimental greenhouse

\section{MATERIALS AND METHODS}

Study Sites: The greenhouse located at Coochbehar (Latitude: $26.2^{\circ} \mathrm{N}$, Longitude: $89.0^{\circ} \mathrm{E}$ ) was selected for the experiment and data collection. The greenhouse is situated $700 \mathrm{Km}$ away from Kolkata in India.

Experimental Greenhouse: The greenhouse was constructed to form single span arched-roof using single layer polyethylene as cover (200 micron thick). The greenhouse was East-West oriented and made by galvanized tubular steel structure. The side view of the experimental greenhouse is shown in Fig. 1. The greenhouse was $20 \mathrm{~m}$ in length and $12.5 \mathrm{~m}$ in width i.e. 250 square meter in ground area. The ridge of the greenhouse was $5.5 \mathrm{~m}$ high from the ground. The greenhouse floor was covered by young plants with a leaf area index of 0.25 . The greenhouse has been provided with gravity fed drip irrigation system for the water requirement of the cultivated plants. The greenhouse microclimate was lines with fog nozzles connected to it. Four fogging lines are equipped along with the length of the greenhouse at 2.5 $\mathrm{m}$ spacing and connected with a distributor line via main pipe line. There are total 32 four-way fog nozzles and each nozzle line consists of 8 nozzles which are located at $2 \mathrm{~m}$ spacing from one another. Fog nozzles are situated at 2.2 $\mathrm{m}$ above the ground surface and spray water to the greenhouse by an electrically operated pump at a pressure of 3 bar and at $0.175 \mathrm{gm} / \mathrm{m}^{2} \mathrm{~s}$ fog rate.

Experimental Measurements: Experiments were conducted on the naturally ventilated greenhouse with both roof vent and side vents open and with intermittent spraying of water fog. Experiments were done considering three different fogging conditions (spraying time to interval time were 1-.5-3.5 $\mathrm{min}, 1-2 \mathrm{~min}$, and 1-3 min respectively). The measurements were conducted at noon (12:10 pm to $1: 00 \mathrm{pm})$ on clear hot sunny days of summer (20 and 21 June, 2015). Following parameters were recorded at $30 \mathrm{~s}$ intervals: (i) outside temperature and 
relative humidity using digital psychrometers (HTC HD304), (ii) inside temperature by aspirated temperature sensor, (iii) outside wind speed using an anemometer (HTC AVM06), (iv) outside solar radiation flux by pyranometer (WACO 206).

$$
Q_{\text {latent }}=\lambda \beta m_{w}
$$

Where $\lambda$ is the latent heat of vaporization, $\beta$ is the fraction of supplied water that would be evaporated into air. The fraction $\beta$ is considered 0.4 .

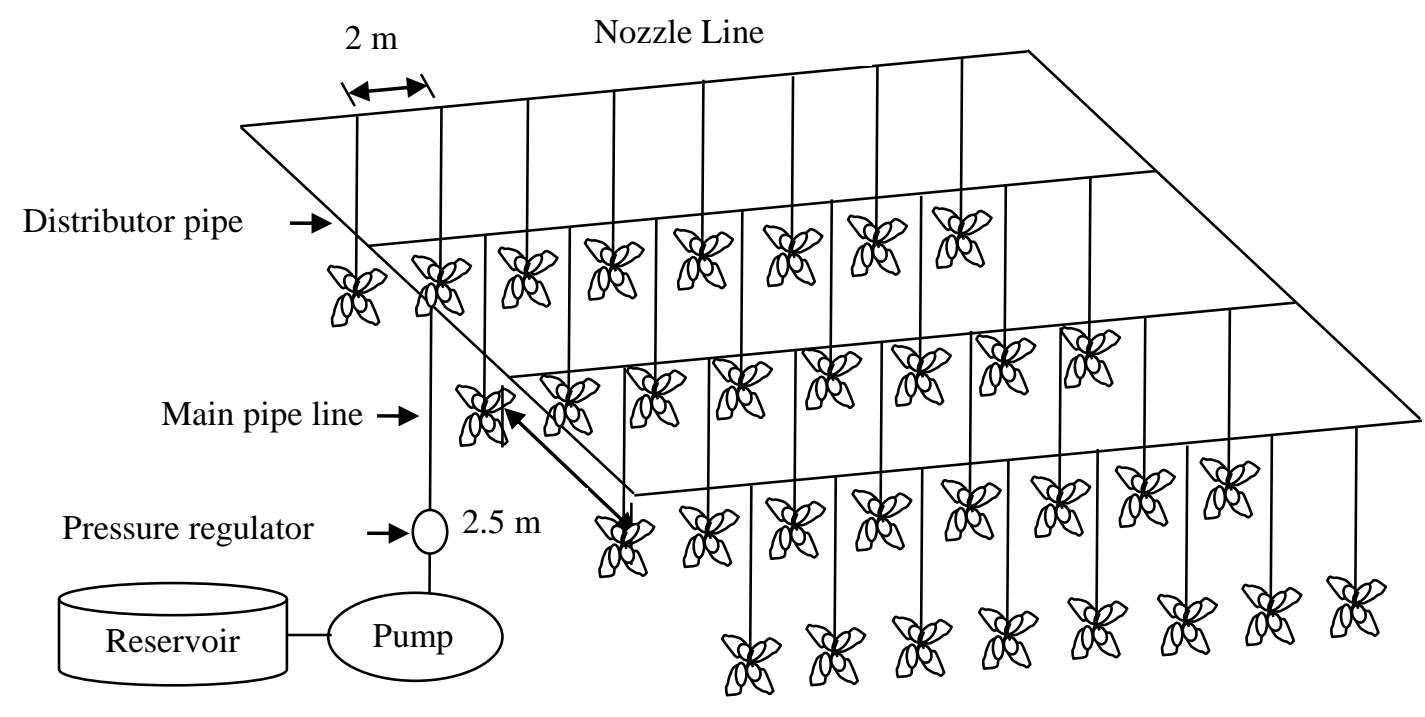

Fig.2: General layout of the fogging system

\section{THERMAL MODELING}

Instantaneous temperature of the greenhouse air is formulated by a simplified energy balance equation as follows

$m_{g} C_{p} \frac{d T_{i}}{d t}=Q_{\text {in }}-Q_{\text {cover }}-Q_{\text {vent }}-Q_{\text {latent }}-Q_{\text {crop }}$

Where $m_{g}$ is the mass of the greenhouse air, $C_{p}$ is the specific heat of greenhouse air, $T_{i}$ is the temperature of the greenhouse air

$\mathrm{Q}_{\text {in }}$ is the net input solar energy to the greenhouse air, and is given by

$\mathrm{Q}_{\text {in }}=\tau \alpha \mathrm{I}(1-\mathrm{SF}) \mathrm{A}_{\mathrm{pa}}$

Where $I$ is the normal radiation, $\tau \alpha$ is the proportion of the solar radiation entering into the greenhouse air, SF shading factor, Apa is the projected area.

$\mathrm{Q}_{\mathrm{cov}}$ is related to the convective heat losses through the cover. Which is given by

$Q_{\text {cover }}=U A_{c}\left(T_{i}-T_{a}\right)$

Where $U$ is the overall heat transfer coefficient and $T_{a}$ is the temperature of the ambient air.

$Q_{\text {vent }}$ represents heat exchange due to air infiltration through the greenhouse ventilators is given as

$Q_{\text {vent }}=\rho_{a} m_{v} C_{p}\left(T_{i}-T_{a}\right)$

$\rho_{a}$ is the density of air and $\mathrm{m}_{\mathrm{v}}$ is the volume flow rate of the ventilated air.

Qlatent refers to the latent heat transfer due to fog evaporation. Which is given by
During the interval period, when pump is off $\beta$ is taken as zero. $\mathrm{m}_{\mathrm{w}}$ is the mass of supplied water by fog nozzles.

The latent heat of vaporization of water $\lambda(\mathrm{J} / \mathrm{Kg})$ is given by $[8]$

$\lambda=10^{3} \times\left(3.4702 \times 10^{3}-5.7352 \times T+1.1687 \times 10^{-2} T^{2}-1.3478 \times 10^{-5} T^{3}\right)$

Where $\mathrm{T}$ is the tempertaure in $\mathrm{K}$.

$\mathrm{Q}_{\text {crop }}$ is related to is energy exchange due to crop transpiration, and given by

$Q_{\text {crop }}=\lambda E_{t}$

Where $E_{t}$ transpiration rate of crop.

Crop transpiration rate of the plants is given by [9]

$E_{t}=A_{f} \operatorname{LAIK}\left(e_{p s}-e_{a}\right)$

Where $\mathrm{A}_{\mathrm{f}}$ is the area of floor and LAI is the leaf areaindex. $\mathrm{e}_{\mathrm{ps}}$ is the saturated vapour pressure corresponding to plant temperature and $\mathrm{e}_{\mathrm{a}}$ is the water vapour pressure corresponding to the greenhouse temperature of air. $\kappa$ is the stomatal boundary layer conductance.

To find the instantaneous temperature of the greenhouse in a particular fogging cycle equation 1 has to be solved. The numerical solution of the differential equation of the greenhouse model required a set of initial conditions which are shown in table1.

In a naturally ventilated greenhouse, ventilation rate is due to mass flow rate due to the thermal buoyancy and wind velocity represented by Ganguly and Ghosh (2009). For fog cooled greenhouse, ventilation rate primarily depends on wind effect, buoyancy effect is being insignificant. A 
linear relationship of the type $y=A x+B$ was assumed for the vent rate calibration and a co-relation was obtained by the fitting a regression line with an observed data points.

Table.1:Input parameters used for the model

\begin{tabular}{|c|c|}
\hline Parameter & $\overline{\text { Values }}$ \\
\hline Proportion of solar energy $(\tau \alpha)$ & 0.52 \\
\hline $\begin{array}{l}\text { Overall heat transfer coefficient } \\
\text { (U) }\end{array}$ & $4.5 \mathrm{Wm}^{-20} \mathrm{C}$ \\
\hline $\begin{array}{l}\text { Covering area of the } \\
\text { greenhouse }\left(\mathrm{A}_{\mathrm{c}}\right)\end{array}$ & $312 \mathrm{~m}^{2}$ \\
\hline Area of greenhouse floor $\left(\mathrm{A}_{\mathrm{f}}\right)$ & $250 \mathrm{~m}^{2}$ \\
\hline Plant Leaf Area Index (LAI) & 0.25 \\
\hline $\begin{array}{l}\text { Mass flow rate of spraying } \\
\text { water }\left(\mathrm{m}_{\mathrm{w}}\right)\end{array}$ & $0.175 \mathrm{gm} / \mathrm{m}^{2} \mathrm{~s}$ \\
\hline $\begin{array}{l}\text { Fraction of fog water to be } \\
\text { evaporate }(\beta)\end{array}$ & 0.4 \\
\hline S.F & 0.75 \\
\hline
\end{tabular}

\section{RESULTS AND DISCUSSION}

To solve the model equations, a program code which is written in $\mathrm{C}$ has been solved. Calculations were made using the measured solar radiation intensity and climatic parameters surrounding the greenhouse for clear sunny days of summer (20 and 21 June 2015). The program code is simulated in the two parts. In first part (spraying time), it simulates the greenhouse temperature profile with time, starting from initial temperature of the greenhouse till the attainment of the final temperature by spraying fog water under natural ventilation. In second part (interval period i.e. $\beta=0$ ), it simulates the greenhouse temperature profile with time, starting from the temperature just after spraying off till the period of the commencement of next fogging cycle under natural ventilation. The ventilation rate of air in a greenhouse microclimate is difficult to predict as it depends on outer environmental conditions. Therefore, its value has been considered as input parameter to simulate the programme.

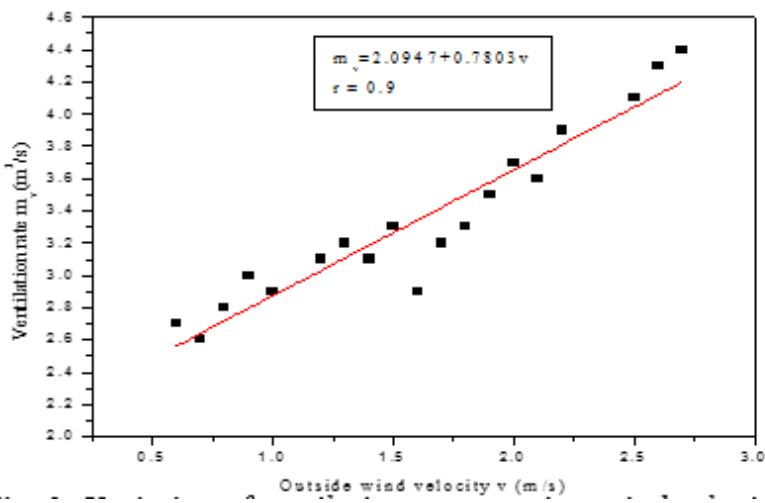

Fig. 3: Variation of ventilation rates against wind velocity

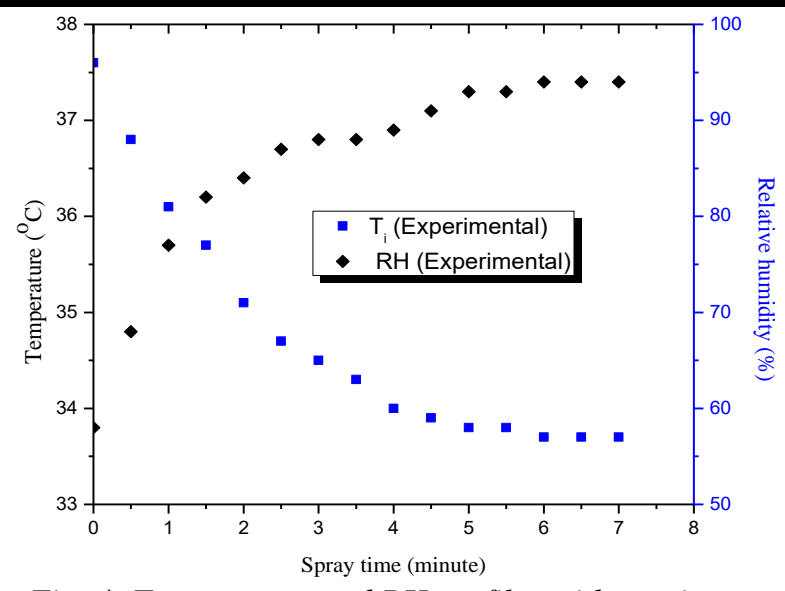

Fig. 4: Temperature and RH profiles with continuous fogging

Figure 3 shows the ventilation rate of air plotted against outside wind velocity from the experimental data. It is seen that ventilation rate was strongly correlated to the outside wind velocity. Since their correlation was good in agreement (coefficient of correlation $r=0.9$ ), a regression equation $\left(\mathrm{m}_{\mathrm{v}}=2.0947+0.7803 \mathrm{v}\right)$ was obtained.

Figure 4 represents the effect of continuous fogging on the greenhouse air temperature under natural ventilation (when side vents and roof vent were $100 \%$ open). It is clearly seen that temperature of the greenhouse air decreases sharply with fogging up to a certain time and thereafter temperature variation is very minimal or nearly constant. It is observed that major reduction of temperature occurs around 2 minute spraying of fog water. However spray (fogging) duration cannot be extended beyond certain time owing to RH limitation required for an operational greenhouse. It was observed that spraying time more than 1.5 minute results in exceeding the RH $80 \%$. With 1 min spraying time $\mathrm{RH}$ can be kept within $75-80 \%$. Thus to maintain the desired level of RH inside the greenhouse 1$1.5 \mathrm{~min}$ spraying time is advisable.

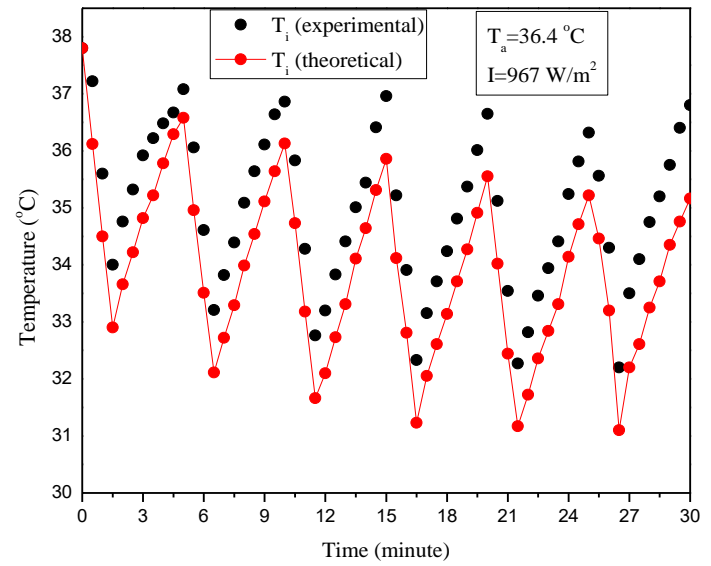

Fig. 5: Greenhouse temperature profiles with a fogging cycle of spray time- spray interval of 1.5-3.5 $\mathrm{min}$ 


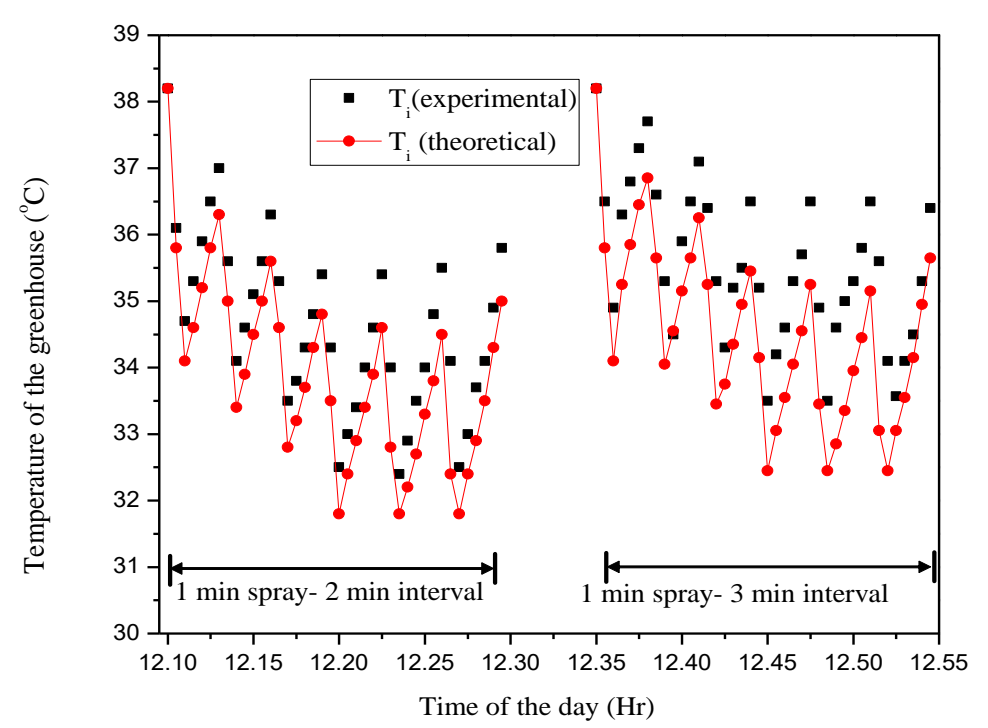

Fig. 6: Temperature profiles for two different fogging cycles in a summer day (21 June 2015)

Figure 5 shows the effect of repeated fogging cycles on greenhouse air temperature, considering a fogging cycle consisting of 1.5 min spray time and 3.5 min interval. Both model predicted temperature profile and actual greenhouse temperature profile are shown in the figure when the side vents and roof vent are fully opened. The experimental data were taken on 21 June 2015. During the experiment, the average global solar radiation intensity was $967 \mathrm{~W} / \mathrm{m}^{2}$, average outside wind velocity was $1.3 \mathrm{~m} / \mathrm{s}$ and the average ambient air temperature was $36.4^{\circ} \mathrm{C}$ and $75 \%$ shading in place. From the figure it is seen that the temperature falls rapidly during fogging time of the cycle and increases during interval periods. The temperature reduction was in the range of 3 to $4{ }^{\circ} \mathrm{C}$ during fogging periods and rise was also 3 to $4{ }^{\circ} \mathrm{C}$ during interval. It is observed that model predicted temperature profile closely matches the experimental temperature profile, the average coefficient of correlation being calculated to be 0.87-0.92

Figure 6 shows greenhouse temperature variations in respect of time for two distinct fogging cycles on a hot summer day of June. The model predicted temperatures are obtained by the prevailing microclimatic data (solar radiation intensity, ambient temperature, wind velocity etc.) as input parameters. The model predicted temperature profiles are approaching nearer to the experimentally obtained temperature profiles. It is seen that measured and predicted temperatures disagreed for some fogging and interval periods. It is due to evaporation rate is assumed constant with time as well as free wind velocity, ambient temperature and solar radiation are considered constant during a fogging cycle in the present model.

Figure 7 and Figure 8 show the influence of fogging cycle configurations on greenhouse average temperature under natural ventilation. The study is done considering of a set of ambient condition, taken by the observed data on a hot and dry day of summer. Global solar radiation intensity, outside wind velocity, ambient $\mathrm{RH}$ and greenhouse initial temperature are assumed as $967 \mathrm{~W} / / \mathrm{m}^{2}, 1.3 \mathrm{~m} / \mathrm{s}, 60 \%$ and $37.8{ }^{\circ} \mathrm{C}$ respectively. It is seen that average temperature depends on the fogging interval period; if the interval period increases, the average temperature increases too. It is due to heat gain by the incoming solar radiation into the greenhouse at interval period. The rate of decrease of temperature is higher for first 4-5 sequential cycles and thereafter temperature variation nearly constant.

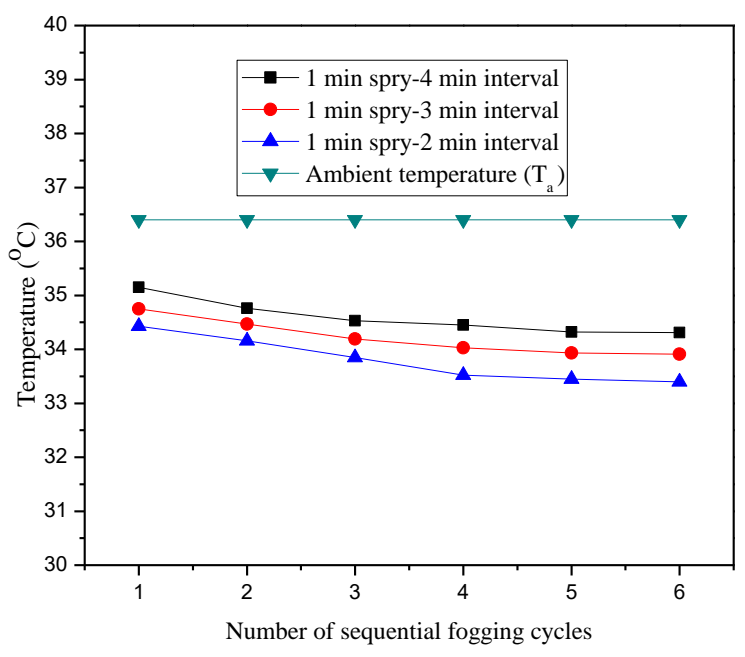

Fig. 7: Influence of spray intervals on greenhouse average temperature for fixed spray time of $1 \mathrm{~min}$ 


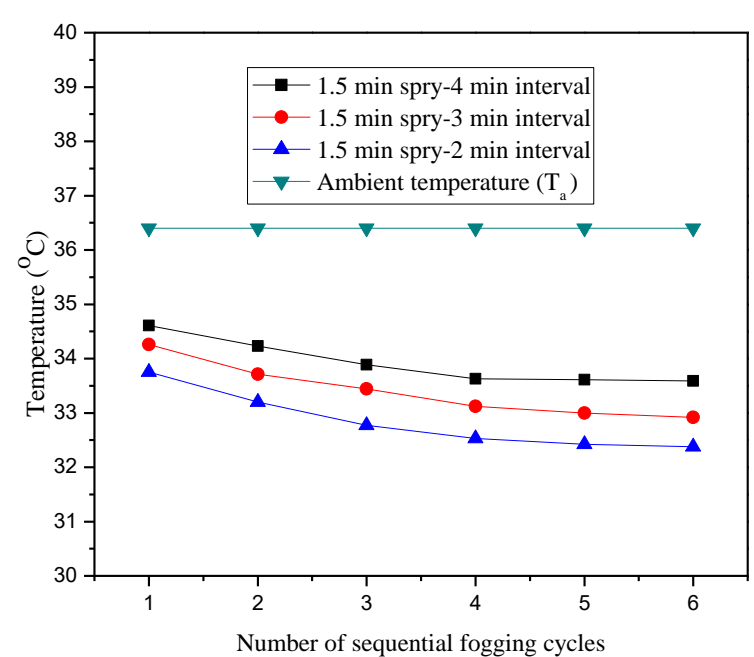

Fig.8: Influence of spray intervals on greenhouse average temperature for fixed spray time of $1.5 \mathrm{~min}$

\section{v. CONCLUSION}

The thermal model developed in the present paper is capable to predict the greenhouse air temperature under different fogging configurations. To validate the thermal model, experimental data have been collected from a 250 $\mathrm{m}^{2}$ polyethylene covered greenhouse. The theoretical prediction of greenhouse air temperatures show a healthy match with measured experimental data. The value of coefficient of correlation is in the range of 0.85 to 0.92 . It is observed that spray time and interval periods are significant for changing greenhouse air temperature. Performance study suggests that fogging cycle of $1.5 \mathrm{~min}$ spray time and 2 min spray interval is best choice, which can be reduced the greenhouse temperature up to $4^{\circ} \mathrm{C}$ when free wind velocity is adequate and ambient condition is hot and dry. Thus it can be concluded that present naturally ventilated fog-cooled greenhouse is able for maintaining suitable environment inside the greenhouse.

\section{ACKNOWLEDGEMENTS}

Authors are grateful to Gopal Chandra Mondal for allowing measurements to be taken in the greenhouse which was established under financial support of Directorate of Agriculture (West Bengal).

\section{REFERENCES}

[1] Arbel, A., Yekutieli, O., Barak, M. (1999). Performance of a Fog System for Cooling Greenhouses. Journal of Agricultural Engineering Research,72: 129-136.

[2] Arbel, A., Barak, M., Shklyar A. (2003). Combination of forced ventilation and fogging systems for cooling greenhouses. Biosystems Engeering,84: 45-55.

[3] Ahmed, M., Abdel-Ghany, A. M., Kozai, T. (2006). Dynamic modeling of the environment in a naturally ventilated, fog-cooled greenhouse. Renewable Energy, 31: 1521-1539.

[4] Abdel-Ghany, A. M., Kozai, T. (2006). Cooling efficiency of fogging systems for greenhouses. Biosystems Engineering, 94: 97-109.

[5] Öztürk, H. H. (2003).Evaporative cooling efficiency of a fogging system for greenhouses. Turk. J. Agric. For, 27:49-57.

[6] Ishigami, Y., Tetsuka, T., Goto, E. (2014). Analysis of aerial environment of a tomato greenhouse equipped with a different fog cooling systems. Journal of agriculture metrology, 70: 127-131.

[7] Li, S., Willits, D., H. (2008). Comparing low-pressure and high-pressure fogging systems in naturally ventilated greenhouses. Biosystems Engeering; 101: 69-77.

[8] Smolik, J., Dzumbova, L., Schwaz, J., Kulmala, M. (2001).Evaporation of ventilated water droplet: connection between heat and mass transfer. Aerosol Science,32: 729-48.

[9] Bot, G. P. A. (1983) Greenhouse climate: from physical process to a dynamic model. $\mathrm{PhD}$ thesis, Agriculture University of Wageningen, The Netherlands.

[10] Ganguly, A., Ghosh, S. (2009). Model development and experimental validation of a floriculture greenhouse under natural ventilation. Energy and Buildings, 41: 521-527.

[11] Abdel Ghany, A. M. (2011). Energy balance equation for natural ventilation of greenhouses under unsteady state conditions. Middle East Journal of Scientific Research, 10: 286-293.

[12] Toida, H., Ohyama, K., Kozai, T., Handarto Hayashi, M. A. (2006). Method for measuring Dry bulb Temperatures during the Operation of a Fog System for Greenhouse Cooling. Biosystems Engineering, 93: 347-351.

[13] Incropera, F. P., Dewitt, D. P. (2013). Fundamentals of Heat and Mass Transfer. J. Wiley \& Sons, New York, 7th edition.

[14] Mirja, A. S., Misra, D., Ghosh, S., (2016). Study the performance of a fogging system for a naturally ventilated, fog-cooled greenhouse, Journal of Energy Research and Environmental Technology, 3(1):19-23. 